\title{
GOSPODARSKO SODELOVANJE AFRIŠKIH DRŽAV S KITAJSKO: PRIMER ANGOLE
}

\author{
dr. Katja Vintar Mally*, Tomaž Gorenc, prof. geografije in zgodovine** \\ * Oddelek za geografijo, Filozofska fakulteta Univerze v Ljubljani, \\ Aškerčeva 2, SI- 1000 Ljubljana \\ ** Ziherlova 8, SI- 1000 Ljubljana \\ e-mail: katja.vintar@ff.uni-lj.si, e-mail:gorenc.tomaz1@gmail.com \\ Izvirni znanstveni članek \\ COBISS 1.01 \\ DOI: 10.4312/dela.40.7.117-131
}

\section{Izvleček}

Prispevek se osredotoča na temeljne značilnosti in najnovejše trende v gospodarskem sodelovanju Kitajske z Afriko, zlasti z vidika geografskih učinkov obsega in strukture trgovinske menjave, tujih neposrednih investicij in razvojne pomoči. V drugem delu članka so predstavljene ključne ugotovitve empirične raziskave v Angoli, ki osvetljujejo odnos Angolcev do gospodarske navezanosti na Kitajsko, kakor tudi do kitajskih priseljencev ter njihove vloge v afriški družbi in gospodarstvu.

Ključne besede: Afrika, Kitajska, Angola, ekonomska geografija, gospodarsko sodelovanje, tuje neposredne investicije

\section{ECONOMIC CO-OPERATION OF AFRICAN COUNTRIES AND CHINA:THE CASE OF ANGOLA}

\begin{abstract}
The paper focuses on the main characteristics and the latest trends in China's economic co-operation with Africa, especially regarding the geographical implications of trade volume and structure, foreign direct investment, and development assistance. The second part of the paper presents key findings of empirical research in Angola, highlighting Angolan perception of economic ties to China as well as attitudes towards Chinese immigrants and their role in African society and economy.
\end{abstract}

Key words: Africa, China, Angola, economic geography, economic co-operation, foreign direct investments 


\section{UVOD}

$\mathrm{Z}$ naravnimi viri bogate afriške države postajajo gospodarsko zanimive za čedalje širši krog držav naložbenic z vsega sveta. Sodelovanje Afrike s Kitajsko ni nedaven pojav, a se hitro krepi, še posebej izrazito v prvem desetletju 21. st. Običajni pogledi na kitajsko udejstvovanje v Afriki so večinoma polarizirani. Medtem ko nekateri poudarjajo pozitiven vpliv naložb na vsestranski napredek celine, drugi svarijo pred neokolonialističnim izkoriščanjem in še posebej opozarjajo na stekanje zaslužkov od prodaje naravnih virov v roke nekaterih diktatorskih režimov. Svarila prihajajo tako iz vrst domačih opozicij kot tudi iz zahodnih držav, ki so do nedavnega same krojile gospodarstvo in politiko afriških držav.

Kitajski način delovanja v Afriki je kot alternativa obstoječemu zahodnemu razvojnemu modelu deležen očitkov predvsem zaradi politike nevmešavanja in nepogojevanja razvojne pomoči. Evropska unija se je postopoma začela zavedati, da kitajske politične odločitve vplivajo na evropske interese na področju energije, naravnih virov, zunanje trgovine, pa tudi na širjenje evropskih vrednot in norm (Lirong, 2011, str. 7), zato je še posebej kritična do Kitajske, a tudi ta ne skopari z očitki na račun evropskega načina sodelovanja $\mathrm{z}$ afriško celino.

Namen pričujočega prispevka je predstaviti temeljne značilnosti in najnovejše trende v gospodarskem sodelovanju Kitajske z Afriko, pri čemer se delo osredotoča zlasti na trgovinsko menjavo, tuje neposredne investicije in razvojno pomoč. $\mathrm{V}$ drugem delu prispevka je izpostavljen primer Angole, kjer je kitajska prisotnost posebej izrazita. $\mathrm{Ob}$ splošnih značilnostih kitajsko-angolskih gospodarskih odnosov je predstavljen segment (66 intervjujev) socialno-ekonomske raziskave, ki smo jo konec leta 2011 izvedli med prebivalci urbanih območij Benguele, Luande in Huamba, kjer pa zaradi priselitev v času angolske državljanske vojne dejansko živijo prebivalci z vseh delov države. V urbanih predelih je tudi uporaba portugalskega jezika bolj razširjena kot na podeželskih območjih, kar je olajšalo raziskovalno delo.

Intervjuji so bili sestavljeni iz dveh sklopov. V prvem so se vprašanja navezovala na dejavnike, ki so pomembni za razvoj Angole: zdravstvo, šolstvo, gospodarstvo, življenjski standard in gospodarsko navezovanje na Kitajsko. Vprašani so tudi podali mnenje o prisotnosti Kitajcev v Angoli in njihovem vplivu v družbi. Drugi sklop vprašanj se je navezoval na podatke o sodelujočih, kamor spadajo navedbe o starosti, etnični pripadnosti, jeziku, veri, civilnem statusu, številu otrok v družini, poklicu, selitvi, politični pripadnosti in izobrazbi. Statistična analiza odgovorov je omogočila vpogled v angolsko percepcijo posameznih razvojnih vidikov, primerjavo s podatki uradne statistike ter nomotetično opredeljevanje občih družbeno-gospodarskih razmer in vzorcev.

Za potrebe pričujočega prispevka predstavljamo le izbrane vidike raziskave s ciljem opredelitve odnosa domačinov do kitajskega gospodarskega udejstvovanja v Angoli in do kitajskih priseljencev. Delovna hipoteza v tem delu preučitve predpostavlja povečevanje kitajskega gospodarskega vpliva ob zaenkrat še skromnem učinku na lokalne družbene odnose. 


\section{GOSPODARSKO SODELOVANJE KITAJSKE ZAFRIKO}

V času svetovne gospodarske krize ostajajo afriški gospodarski obeti ugodni, kar se med drugim kaže tudi v gospodarski rasti in naraščajočem gospodarskem sodelovanju s tujino. V letu 2012 so finančni prilivi v Afriko dosegli zgodovinsko najvišjo vrednost 186,3 milijarde USD (2011: 158,3 milijarde USD). Ob davčnih prihodkih so prav tuje neposredne investicije, portfeljske naložbe, uradna razvojna pomoč in nakazila emigrantov glavni viri financiranja afriških držav. Vrednost omenjenih finančnih prilivov se je po letu 2001 povečala za štirikrat in v letu 2012 dosegla 9,2 \% afriškega BDP (African economic outlook 2013, 2013, str. 44). Sočasno se je za približno štirikrat povečala tudi vrednost afriškega izvoza. Evropska unija in ZDA so glavno izvozno tržišče za afriške države, vendar kitajsko, brazilsko, indijsko in druga hitro rastoča gospodarstva naglo prevzemajo vse večji delež (African economic outlook 2013, 2013, str. 66). Slednje pa ne velja le za zunanjo trgovino, ampak tudi za druge oblike gospodarskega sodelovanja.

Kitajska je v zadnjih letih postopoma postala največja trgovinska partnerica Afrike. Po podatkih kitajske bele knjige o gospodarskem sodelovanju z Afriko (China-Africa economic ..., 2013) je Afrika za Kitajsko glavni vir uvoza, drugo največje tuje tržišče za kitajske gradbene posle in četrta največja destinacija kitajskih investicij. V letu 2012 je obseg menjave med Kitajsko in Afriko dosegel zgodovinski višek pri vrednosti

Slika 1: Obseg menjave med Kitajsko in Afriko v obdobju 2000-2012

Figure 1: China-Africa trade volume 2000-2012

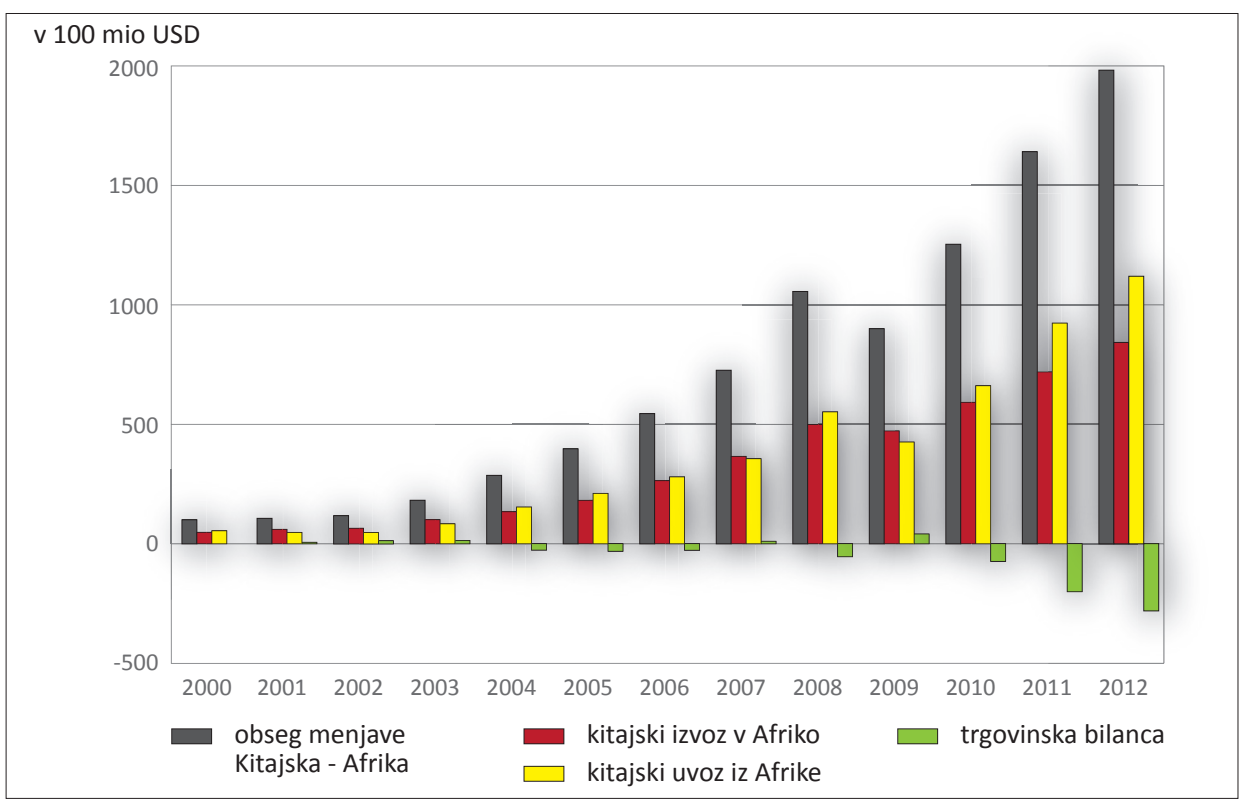

Vir/Source: China-Africa economic ..., 2013, str. 4 
198,5 milijarde USD in se glede na predhodno leto povečal kar za 19,3 \%. Od tega je kitajski izvoz v Afriko znašal 85,3 milijarde USD, sočasno pa je Afrika na Kitajsko izvozila za 113,2 milijarde USD. Obseg menjave stalno narašča in Afrika pri tem beleži čedalje večji presežek v trgovinski bilanci (slika 1). Če v bilanci ne bi upoštevali nafte, pa bi Afrika denimo v letu 2011 izkazovala okrog 28 milijard USD primanjkljaja. Več kot tri četrtine afriškega izvoza odpade na nafto, zemeljski plin, rude in kovine iz vsega petih držav (Sudan, Angola, Egipt, Nigerija in Južnoafriška republika). V obratni smeri je kitajski izvoz v Afriko bistveno bolj raznolik, in sicer tako po destinaciji kot tudi vrsti blaga (Between extremes ..., 2012).

Trgovinska menjava med Kitajsko in Afriko je bistveno pomembnejša za slednjo, saj Kitajska v Afriko izvozi le 4,16 \% celotne vrednosti svojega izvoza, delež uvoza iz Afrike pa dosega le 6,23 \%. Obratno na Kitajsko odpade kar 18,07 \% celotne vrednosti afriškega izvoza, medtem ko afriške države iz Kitajske uvozijo 14,11 \% od vrednosti celotnega uvoza celine (China-Africa economic ..., 2013). Kitajska je postala najpomembnejše izvozno tržišče za države, kot so Demokratična republika Kongo, Kongo, Sudan, Angola, Mavretanija in Zambija. Po drugi strani so na primer za Čad in Lesoto še vedno najpomembnejši izvozni cilj ZDA, Gvineja Bissau pa največ izvozi v Indijo (kar 90 \%; African economic outlook 2013, 2013, str. 19). Čeprav je trgovanje s Kitajsko in drugimi hitro rastočimi gospodarstvi na splošno v naglem vzponu, pa ostajajo gospodarsko razvite države še vedno najpomembnejši izvozni trgi. V ZDA je bilo leta 2011 namenjenega 15,8 \% afriškega izvoza, v države Evropske unije pa skupno 32,5 \% izvoza. Afriške države so tega leta iz ZDA uvozile 6,8 \%, iz držav Evropske unije pa 32,4 \% vrednosti uvoza (UNCTAD handbook ..., 2012, str. 90-91). Kljub skoraj tretjinskemu deležu menjave med Evropsko unijo in afriškimi državami so deleži posameznih držav članic Evropske unije bistveno manjši od kitajskega deleža. Večina statističnih virov navaja, da je Kitajska leta 2009 prvič prehitela ZDA in tako postala največja trgovinska partnerica Afrike.

O gospodarskih odnosih Kitajske in Afrike veliko razkrije tudi analiza strukture uvoza in izvoza. Kitajska iz Afrike uvaža pretežno goriva ter rude in drage kamne, v afriške države pa izvažajo večinoma le končne izdelke (preglednica 1). Kitajski gospodarski razvoj je odvisen od porabe velikih količin energentov, ki jih zagotavljajo tudi nekatere afriške države. Kitajska je tako leta 2012 iz afriških držav uvozila okrog 1,3 milijona sodčkov nafte dnevno in odkupila dobrih 18 \% vsega afriškega izvoza nafte. Podoben je tudi delež, ki ga afriška nafta zavzema v celotnem uvozu nafte na Kitajsko. Kitajska kljub temu še vedno največ nafte kupuje v državah ob Perzijskem zalivu, medtem ko Afrika proda največ nafte v Evropo (okrog 40 \%; BP statistical ..., 2013). Evropske države poleg goriv v večji meri kot Kitajsko zanimajo tudi afriški končni izdelki ter kmetijske surovine in hrana (Vintar Mally, 2012). Afriško povpraševanje po industrijskih izdelkih je razmeroma veliko in glede na gospodarsko strukturo razumljivo, saj ima večina držav zelo slabo razvito industrijo, vendar ti v trgovinski menjavi Afrike $\mathrm{z}$ drugimi deli sveta nimajo tako absolutno prevladujoče vloge. Afriške države namreč uvažajo tudi veliko hrane, tiste brez lastnih fosilnih goriv pa tudi goriva. 
Preglednica 1: Struktura uvoza in izvoza blaga v letu 2011

Table 1: Import and export structure in 2011

\begin{tabular}{|l|c|c|c|c|}
\hline & $\begin{array}{c}\text { Afriški izvoz - } \\
\text { svet (\%) }\end{array}$ & $\begin{array}{c}\text { Afriški izvoz na } \\
\text { Kitajsko (\%) }\end{array}$ & $\begin{array}{c}\text { Afriški uvoz - } \\
\text { svet (\%) }\end{array}$ & $\begin{array}{c}\text { Afriški uvoz iz } \\
\text { Kitajske (\%) }\end{array}$ \\
\hline Goriva & 57,4 & 59,6 & 14,5 & 0,4 \\
\hline Rude in dragi kamni & 13,8 & 23,4 & 3,2 & 1,6 \\
\hline Kmetijske surovine & 2,4 & 4,0 & 1,4 & 0,4 \\
\hline Hrana & 8,6 & 1,5 & 14,4 & 3,1 \\
\hline Končni izdelki & 16,3 & 3,4 & 61,1 & 94,4 \\
\hline Vsi proizvodi & 100,0 & 100,0 & 100,0 & 100,0 \\
\hline
\end{tabular}

Vir/Source: UNCTAD handbook ..., 2012

Medtem ko so kitajske investicije na afriški celini zaželene, to ne velja povsem za njihove industrijske proizvode. Kitajska industrija oskrbuje afriški trg s poceni proizvodi: avtomobili, jeklom, telekomunikacijskimi sredstvi, predvsem pa s tekstilom in obutvijo, kar uničuje afriške proizvajalce tega blaga (Atlas der Globalisierung, 2009). Gospodarski odnosi med Afriko in Kitajsko so ob tem deležni tudi očitkov, da ne prihaja do prenosa tehnologij in znanj ali izboljšanja produktivnosti. Zaradi nižje cene delovne sile vse več kitajskih podjetij preučuje možnost selitve proizvodnje v Afriko, kjer na trg delovne sile vsako leto na novo vstopi od sedem do deset milijonov ljudi. Poleg obsežnega afriškega trga je vabljiv tudi brezcarinski dostop do severnoameriškega in evropskega trga, ki ga afriške države lahko uveljavljajo po posebnih sporazumih. Dejansko pa se delovna mesta v večji meri še ne selijo v Afriko. Bistveno večji je učinek izgubljanja delovnih mest zaradi uvoza poceni kitajskega blaga, ki uničuje mala in srednje velika afriška podjetja. Samo v Južnoafriški republiki naj bi v prejšnjem desetletju zaradi tega izgubili 78.000 delovnih mest v industriji (Between extremes ..., 2012). Iz nekaterih afriških držav poročajo celo o uradnih kampanjah omejevanja delovanja kitajskih trgovcev na drobno, ki prodajajo poceni in pogosto tudi ceneno blago, po katerem je zaradi šibke kupne moči večine afriškega prebivalstva veliko povpraševanja.

Ob utrjevanju gospodarske prisotnosti želi kitajska vlada izboljšati tudi svojo javno podobo. $V$ ta namen izvaja denimo program izobraževanja 30.000 afriških strokovnjakov na različnih področjih (t. i. African Talents Programme), podeljuje štipendije (Ighobor, 2013), kitajske banke pa namenjajo večmilijardna posojila afriškim vladam. Samo v letu 2012 je Kitajska afriškim državam za naslednje triletno obdobje obljubila 20 milijard USD posojil za infrastrukturo, kmetijstvo in industrijo, s čimer utegne postati največja finančna podpornica Afrike. Posojila so praviloma ugodna, z nizko obrestno mero, netransparentna in zavarovana $\mathrm{z}$ dohodki od prodaje naravnih virov. Iz tega izhajajo očitki zahodnih držav, da Kitajska spodbuja korupcijo in razvojno pomoč izkorišča za promocijo lastnih gospodarskih interesov ter neokolonialistično izkoriščanje virov. Pogosto se ob tem preprosto spregleda raznovrstnost finančnih transakcij med Afriko in Kitajsko (Between extremes ..., 2012). 
Kitajska namenja Afriki zelo velik delež svoje razvojne pomoči; v letu 2009 kar 45,7 \% oziroma bistveno več kot geopolitično bližjim azijskim državam $(32,8$ \%; Lirong, 2011, str. 9). Največ razvojne pomoči namenja za izgradnjo afriških pristanišč, cest in železniških prog, kakor tudi za oskrbo z energijo in telekomunikacijami (Kinšasa je denimo že priklopljena na omrežje z optičnimi kabli). S tem odpira dostop tudi drugim investitorjem s celega sveta, kar povečuje konkurenco in posledično tudi možnost, da bodo lahko domačini izkupiček od izkoriščanja naravnih virov bolj učinkovito izkoristili sebi v prid. Kljub temu so Afričani večinoma kritični do kitajske prisotnosti, zlasti zaradi nepreglednosti poslovanja in zanemarjanja socialnih in okoljskih problemov (Atlas der Globalisierung, 2012, str. 140).

Kitajska podjetja so zelo uspešna pri pridobivanju velikih gradbenih poslov v Afriki, kot je na primer 1,5 milijarde USD vreden projekt posodobitve železniškega omrežja v zahodni Nigeriji ali 400-milijonska prodaja lokomotiv južnoafriškim železnicam (Ighobor, 2013). Samo za obnovo infrastrukture v Angoli je Kitajska zagotovila dve milijardi USD kreditov, investira pa tudi v proizvodnjo bakra v Zambiji, rudnike premoga v Zimbabveju, črpanje nafte v Sudanu in Gabonu, nakupe zemljišč v Ugandi, Kamerunu, Etiopiji in na Madagaskarju. Poleg tega daje še subvencije za gradnjo novih pregradnih jezer, cest in javnih ustanov v več afriških državah (Atlas der Globalisierung, 2012, str. 140). Vlaganje v infrastrukturo (prometne poti, pristanišča, elektrarne, predelovalne obrate ipd.) in izkoriščanje naravnih virov, zlasti mineralnih surovin, sta v Afriki večinoma tesno povezana. Rudarstvo je na afriško celino pritegnilo bistveno več naložb kot katerakoli druga gospodarska dejavnost (Hobbs, Salter, 2006).

Med letoma 2009 in 2012 so se kitajske neposredne investicije v Afriki povečale z 1,44 na 2,52 milijarde USD, s povprečno letno rastjo 20,5\%. Več kot 2000 kitajskih podjetij naj bi bilo investicijsko prisotnih v več kot petdesetih afriških državah. Skoraj tretjino vseh investicij usmerjajo v rudarstvo (30,6 \%), sledijo finančni sektor $(19,5 \%)$, gradbeništvo $(16,4 \%)$ in industrija $(15,3 \%)$. Nekaj odstotkov naložb se steka še v poslovne storitve $(5,0 \%)$, raziskave $(4,1 \%)$, trgovino $(2,7 \%)$ ter kmetijstvo, gozdarstvo in ribolov (2,5 \%; China-Africa economic ..., 2013, str. 5- 6). V obdobju 2010-2012 je bila tudi po zaslugi kitajskih naložb in vseh investicij v raziskovanje in izkoriščanje naravnih virov Afrika edina velika svetovna regija, ki je stalno beležila rast tujih neposrednih investicij. Te so leta 2012 dosegle 50 milijard USD oziroma 3,7-odstotni svetovni delež. Med državami v razvoju na afriški celini največ investirajo Malezija, Južnoafriška republika, Kitajska in Indija. Malezija je imela leta 2011 za skupno 19 milijard USD naložb, zlasti v kmetijstvo (pretežno na vzhodu in zahodu celine) ter finančni sektor (največ na Mauritiusu). Sledili sta ji Južnoafriška republika z 18 milijardami USD in Kitajska s 16 milijardami USD naložb (World investment report 2013, 2013). Večjo vrednost naložb v Afriki od navedenih držav so imele v preteklih letih le Francija, ZDA in Velika Britanija (Economic development ..., 2013).

Še bolj zgovoren je podatek, da se je med letoma 2003 in 2011 vrednost kitajskih tujih neposrednih investicij v Afriki povečala za tridesetkrat, in sicer s 491 milijonov na 14,7 milijarde USD. Čeprav politiko odnosov z Afriko vodi kitajski državni vrh, pa v praksi državna in zasebna podjetja pogosto tekmujejo za posle $\mathrm{v}$ gradbeništvu ali rudarstvu. 
Naložbe na tujem in razvojna pomoč spodbujajo industrijsko rast in diverzifikacijo kitajskega gospodarstva, številni Kitajci pa tudi sami iščejo gospodarske priložnosti v tujini. Po različnih ocenah naj bi na afriški celini živelo od 500.000 do 1.000 .000 kitajskih priseljencev. Evidence so nezanesljive, delavci pa ostajajo v afriških državah tudi po preteku vizumov. Pogodbeni delavci velikih zasebnih ali državnih podjetij le redko pridejo v stik $\mathrm{z}$ domačini, zato ti večinoma poznajo le kitajske trgovce na drobno ali male podjetnike, delujoče na lokalnem trgu samostojno, brez povezave z matično državo (Between extremes ..., 2012). Prav na podlagi stikov z malimi kitajskimi podjetniki si Afričani oblikujejo mnenje o Kitajcih in odnos do kitajske prisotnosti, kakor je razvidno tudi iz podrobnejše preučitve na primeru Angole.

\section{KITAJSKO-ANGOLSKI GOSPODARSKI IN DRUŽBENI ODNOSI}

Angola je država Podsaharske Afrike, ki je zaradi lege ob Atlantskem oceanu in na prehodu Srednje v Južno Afriko v primerjavi z notranjostjo celine že razmeroma zgodaj prišla v stik s tujci. Površje države je izrazito planotasto in se od atlantske obale v stopnjah dviguje proti platoju Bié v osrednjem delu države. Po angolskem ozemlju poteka tudi ločnica med Nizko Afriko na severu in Visoko Afriko na jugu. Površje je na splošno ugodno za poselitev, toda dandanes večina prebivalstva živi v obalnih mestih, kar je posledica zgodovinskih dogodkov in državljanske vojne, ki je bila najbolj intenzivna v notranjosti Angole. Večja gostota prebivalstva je tudi na platoju Bié, medtem ko je skrajni jug države zaradi sušnega podnebja le redko poseljen. Zaradi reliefne izoblikovanosti imajo reke velik strmec in s tem tudi velik hidroenergetski potencial, visoke uravnave pa so ugodne za kmetijstvo. Angola ima zaradi obilja naravnih virov, predvsem nafte in diamantov, za afriške države razmeroma visok bruto domači proizvod, naravna bogastva pa so v kolonialni preteklosti in sedanjosti vseskozi igrala pomembno vlogo.

Socialno-ekonomske razmere v 20-milijonski državi dobro predstavi indeks človekovega razvoja, ki je leta 2012 znašal vsega 0,508 in Angolo uvrstil v skupino držav z nizkim indeksom, na skromno 148. mesto od 186 držav z razpoložljivimi podatki. V zadnjem petletnem obdobju se je vrednost indeksa le minimalno izboljšala (za 0,031). Primerjalno najslabše razmere izkazuje država na področju izobraževanja, saj imajo Angolci v povprečju le 4,7 razreda osnovne šole, pismenih pa je samo $70 \%$ starejših od 15 let. Zdravstvene razmere se zrcalijo v pričakovanem trajanju življenja ob rojstvu, ki je bilo v letu 2012 ocenjeno na vsega 51,5 let. S skupno 4812 USD bruto nacionalnega dohodka na prebivalca se Angola sicer uvršča na 113. mesto na svetu, vendar se prihodki razmeroma slabo pretvarjajo v blaginjo za večino državljanov, saj v pogojih ekstremne revščine živi več kot polovica prebivalstva (Human development report ..., 2013).

Angola je ena od mnogih afriških držav, ki se je v drugi polovici 20. st. srečala s procesom dekolonizacije in kopico razvojnih, političnih ter ekonomskih problemov. Na splošno so izpraznjen gospodarski prostor, ki so ga pustile kolonialne velesile, nadomestile 
slednje z raznimi združenji ali pa nove, ideološko usmerjene akterke hladne vojne. Po osamosvojitvi Angole leta 1975 je državo zajela državljanska vojna, v kateri so sodelovale različne države, razdeljene na ideološke pole. Sodelovanje je bilo tako politično in vojaško kot tudi ekonomsko. V tem obdobju sta imeli največji vpliv na Angolo Kuba in Sovjetska zveza. Po razpadu slednje leta 1991 in s koncem hladne vojne je pričela dobivati vedno večji gospodarski vpliv Kitajska, njena vloga pa se je še posebej povečala $\mathrm{v}$ novem tisočletju.

$\mathrm{V}$ angolskem primeru je vidna izrazita korelacija med politiko in gospodarskim sistemom, ki se je kazala že $\mathrm{v}$ času državljanske vojne, ko je vlada stremela $\mathrm{k}$ hitrim in rednim dohodkom od prodaje neobnovljivih virov. Če je v času kolonializma največjo vlogo v gospodarstvu igrala pridelava kave, temelji sodobno angolsko gospodarstvo na izvozu nafte. Cene črnega zlata so že v zadnjih desetletjih 20. st. vztrajno rasle, obnovljivi viri pa so bili potisnjeni na obrobje. Angola je to spreminjajočo se gospodarsko usmerjenost pridobila v vojnem obdobju, zaradi česar je angolsko gospodarstvo dandanes zelo homogeno, s (pre)močno prevlado nafte in diamantov. Odvisnost od nafte in naftnih derivatov je velika, saj je z njihovim izvozom leta 2011 Angola ustvarila kar 98,9 \% celotne vrednosti izvoza (UNCTAD handbook ..., 2012). Neugodnost te odvisnosti se je jasno pokazala v padcu gospodarske rasti v času recesije leta 2009, ko so cene nafte padle na vseh svetovnih trgih.

Po premirju, ki so ga podpisali po smrti opozicijskega voditelja Jonasa Savimbija (UNITA) leta 2002, je ta afriška država doživela velik gospodarski vzpon (slika 2). To se je kazalo pri vrednosti BDP na prebivalca, ki je vse do gospodarske krize leta 2009 naraščal linearno. Sočasno je gospodarsko rast spremljalo zmanjševanje inflacije s $300 \%$ leta 1998 na $12 \%$ leta 2006. Glavni razlog za takšen vzpon ni bil le konec dolgotrajne vojne, pač pa tudi velika prisotnost kitajskih investicij v povojnih letih. Prioriteta angolske vlade je bila obnovitev države, za kar so potrebna finančna sredstva. Tukaj je priskočila 'na pomoč' Kitajska, ki je v relativno kratkem času v Angolo investirala veliko kapitala in se prebila na prvo mesto med angolskimi investitorji. Po besedah Zhanga Boluna, kitajskega veleposlanika v Luandi, v intervjuju za časnik Journal de Angola je Kitajska od leta 2003 $\mathrm{v}$ to afriško državo investirala že 15 milijard USD (Bessa, 2011).

Kitajske investicije zagotovo ne bi bile tako visoke, če bi Angola ne bila tako bogata $\mathrm{z}$ nafto, diamanti in drugimi surovinami. Angola je namreč postala največja afriška partnerica Kitajske pri izvozu nafte, leta 2009 je ta azijska velesila prehitela tudi ZDA pri nakupih angolskih diamantov. Povezave med ugodnimi in velikimi krediti ter izvozom nafte in drugih surovin so očitne. Na ta način lahko Angola hitro podleže kitajskemu pragmatičnemu kapitalizmu in pade $\mathrm{v}$ veliko odvisnost. Kitajska je obudila angolsko gospodarstvo, ko je začela vlagati milijarde v politično nestabilno državo. $\mathrm{V}$ zameno si je zagotovila stalen vir surovin in nov trg, na katerega prihajajo kitajski delavci in izdelki. Med slednjimi prevladujeta tekstil in tehnologija, pri kateri imajo Kitajci tudi monopol. Zaradi premajhne konkurence so cene pogosto zasoljene, kljub slabši kakovosti izdelkov. 
Slika 2: Gospodarska rast Angole v obdobju 2002-2011

Figure 2: Economic growth in Angola, 2002-2011

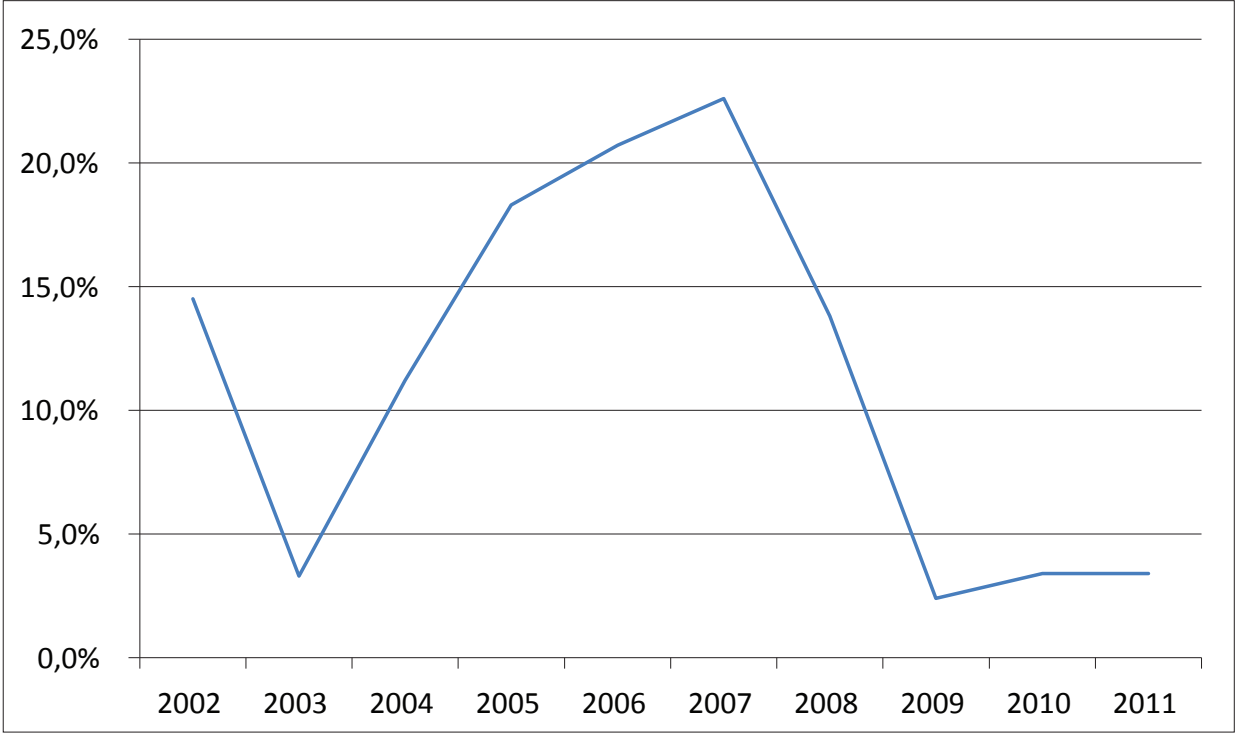

Vir/Source: Campos, Vines, 2008, str. 1

Ali je dobro, da se Angola gospodarsko v tolikšni meri navezuje na to azijsko velesilo? V intervjujih z domačini je $35 \%$ sodelujočih odgovorilo, da je to sodelovanje nekakšen dvorezen meč. Menili so, da je kratkoročno gospodarska povezava s Kitajsko dobra, saj pomaga pri razvoju Angole. Po drugi plati opažajo veliko negativnih vplivov, ki se bodo pokazali šele na dolgi rok. Primeri navedenih negativnih vplivov so bili večinoma družbene narave, kot sta intenzivno naseljevanje, izkoriščanje Angolcev, poleg tega je večina kitajske tehnologije, ki pride v državo, le v kitajščini. Podobni komentarji so bili prisotni tudi pri petini vprašanih, ki so ocenili angolsko-kitajsko navezovanje kot slabo. Slednji so še dodali, da se ni dobro navezovati le na eno državo in da imajo kitajski priseljenci zaposlitev z dobrim plačilom, medtem ko je mnogo Angolcev brez dela. Gospodarska naveza se po mnenju vprašanih dolgoročno obrestuje le Kitajski, zato so jo označili za novodobni kolonializem. Nek angolski učitelj, ki je prav tako sodeloval v intervjujih, je to povzel s primerom iz obdobja velikih geografskih odkritij, ko so tudi Portugalci sprva prišli v njihove kraje zgolj trgovat in pomagat nekaterim ljudstvom (Gorenc - intervjuji ..., 2011). 
Slika 3: Mnenje domačinov o navezovanju Angole na Kitajsko

Figure 3: Angolan perception of economic ties to China

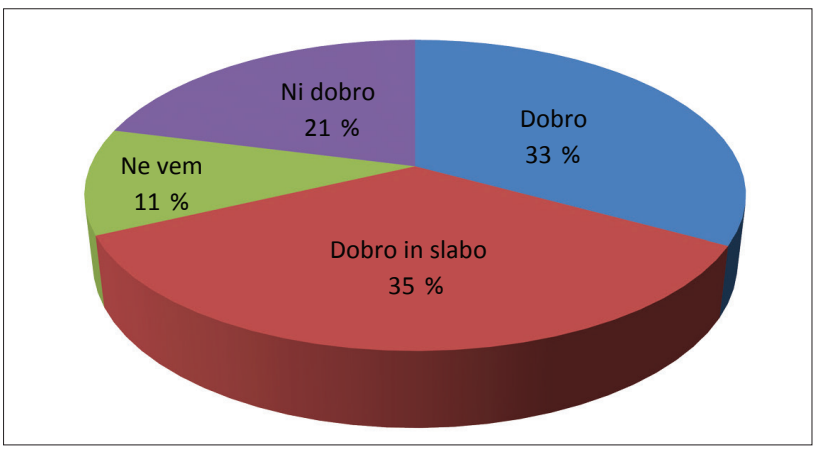

Vir/Source: Gorenc - intervjuji v Bengueli, Huambu in Luandi (2011)

Slika 4: Mnenje domačinov o razlogih za delovanje Kitajcev v Angoli Figure 4: Chinese activities in Angola as perceived by locals

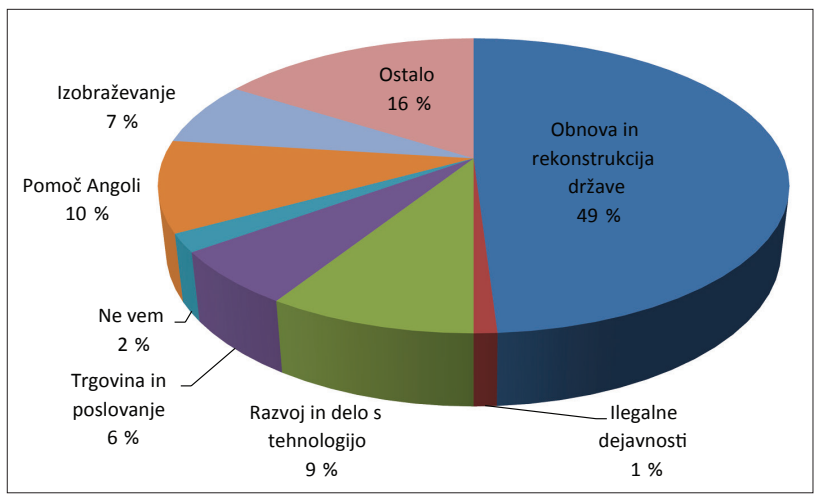

Vir/Source: Gorenc - intervjuji v Bengueli, Huambu in Luandi (2011)

Kitajska podjetja v primerjavi z drugimi tujimi podjetji kljub številnim projektom niso ustvarila veliko delovnih mest za Angolce. Vzrok za to je delno v pomanjkanju ustrezno izobražene delovne sile v Angoli, vendar domačini ne prevladujejo niti na nižje kvalificiranih delovnih mestih, kot so na primer gradbena dela. Kitajski priseljenci so namreč dobro zastopani tudi na gradbiščih (Horta, 2011). Kitajska delovna sila je v gradbeništvu očitno boljša in cenejša, še posebej, če držijo namigi, da je med kitajskimi delavci veliko zapornikov, ki v Angoli služijo svojo kazen. Tudi več kot polovica sodelujočih v intervjujih je na vprašanje, kaj Kitajci delajo v Angoli, odgovorila, da delajo na področju obnove. 
Temu so sledili še odgovori: pomoč Angoli, trgovina, poslovanje ter tehnologija, zlasti še zaradi velikega števila servisov in trgovinskih izložb z računalniško opremo (Gorencintervjuji ..., 2011).

Slika 5: Odnos domačinov do kitajskih priseljencev

Figure 5: Attitudes of local population towards Chinese immigrants

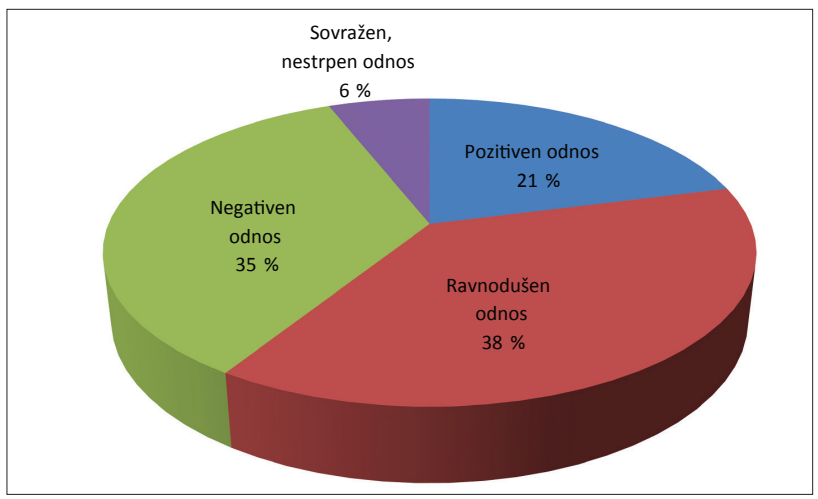

Vir/Source: Gorenc - intervjuji v Bengueli, Huambu in Luandi (2011)

Po besedah kitajskega veleposlanika v Angoli naj bi bilo dandanes v tej podsaharski državi več kot 70.000 kitajskih priseljencev (Bessa, 2011). Po poročilu Angolske tiskovne agencije (ANGOP) je Angola v pol leta odobrila več kot 22.000 kitajskih vizumov, to pa kaže na bistveno večje število kitajskih priseljencev v Angoli (po nekaterih podatkih tudi do 250.000; News24 ..., 2013). Dejstvo je, da azijski priseljenci postajajo vse bolj vplivni v angolski družbi. Ker je migracijski saldo države pozitiven zlasti zaradi kitajskih priseljencev, se bo tovrsten vpliv še povečeval. Trenutno je kitajski vpliv večji na gospodarskem kot na družbenem področju. Bistveni razlog za to je neznanje portugalskega oziroma kitajskega jezika v vsakdanjem življenju. Na gradbišču ali naftni ploščadi ni pomembno znanje portugalskega jezika, saj so stroji in večina sodelavcev kitajski. Posledično azijski priseljenci niso močno prisotni v angolskem šolstvu ali zdravstvu, za razliko od Kubancev, katerih jezik je bližje portugalščini. To dokazuje tudi sama interakcija domačinov s Kitajci. Kar tri četrtine intervjuvancev nima tesnejših socialnih stikov s Kitajci. Sodelujoči, ki so imeli stike s kitajskim prebivalstvom, so kot razlog navedli delo (avtomobilske delavnice in gradbišča) ter obiske trgovin (fotokopirnice, prodaja tehničnih naprav). Če bi bil jezik manjša ovira, bi bil kitajski vpliv v družbi zagotovo večji. Kljub temu ima večina domačinov jasno oblikovan odnos do kitajskih priseljencev. Več kot tretjina sogovornikov je v intervjuju izrazila negativen, $6 \%$ pa celo nestrpen odnos do azijskih prišlekov. Med najpogostejšimi razlogi sta ti dve skupini navedli novo kolonizacijo, jemanje služb domačinom, krajo zemljišč ... Petina vprašanih je na Kitajce gledala pozitivno, češ da so tu samo začasno in Angoli pomagajo (Gorenc - intervjuji ..., 2011). 
Angola je v zadnjih letih dosegla vrh 'naftnega booma'. Po napovedih bo naftno blagostanje trajalo še dve desetletji, potem bo angolsko monostrukturno gospodarstvo na veliki preizkušnji (Angola ..., 2007). Vsi ti dogodki bodo zagotovo vplivali na prisotnost kitajske pragmatične politike in njenega kapitala v Angoli. Glede na trend povečevanja kitajskega vpliva $\mathrm{v}$ angolskem gospodarstvu $\mathrm{v}$ zadnjih letih se bo ta zagotovo povečal tudi v angolski družbi. Vsi kitajski priseljenci, ki so v tej afriški državi pričeli novo življenje in imajo tu trgovine ter podjetja, se verjetno ne bodo kar tako vrnili v Azijo, domačini pa bodo verjetno na kitajske migracije in druge družbene procese gledali z vse manj simpatije do azijskih priseljencev.

\section{SKLEP}

Afrika je obsežen trg z več kot milijardo prebivalcev, ki se iz leta v leto še povečuje, prebivalstvo pa je pretežno mlado in vse bolj urbano. Poleg tega celina ponuja obilico naravnih virov, zato ne preseneča naraščajoče zanimanje Kitajske za afriški trg in surovine. Za investitorje postaja zanimiva tudi poceni delovna sila, vendar se to še ni odrazilo v večjih selitvah industrijske proizvodnje in ustvarjanju novih delovnih mest za Afričane. Očitno še vedno prevladujejo drugi lokacijski dejavniki, glede katerih je Afrika v primerjavi z drugimi državami v razvoju manj konkurenčna (npr. slabša prometna infrastruktura in višji transportni stroški, velik delež neizobražene delovne sile, težave pri oskrbi z električno energijo ipd.).

Vse oblike gospodarskega sodelovanja Kitajske in afriških držav so v hitrem porastu, a se trgovinska menjava bolj osredotoča na države, ki so vodilne izvoznice goriv in rud na Kitajsko. V obratni smeri kitajsko blago in investicije dosežejo večino afriških držav. Angola je tipičen primer države, ki skoraj celotno vrednost izvoza ustvari z nafto, kar pa lahko ob nihanju povpraševanja in cen na svetovnem trgu pomeni veliko tveganje za zaslužke. Pri proizvodnji nafte kot kapitalsko intenzivni dejavnosti z majhnim številom delovnih mest je povsem odvisno od vlad, če in kako uspejo zaslužke pretvoriti v večjo blaginjo svojih prebivalcev ter preprečiti, da končni rezultat ni zgolj izčrpavanje naravnih virov, bogatenje elit in posledično povečanje nevarnosti konfliktov. V tej luči bi bile v prihodnosti bistveno bolj zaželene kitajske naložbe v industrijo, nova delovna mesta in izvoz afriških proizvodov $\mathrm{z}$ večjo dodano vrednostjo.

Medtem ko je Kitajska na afriški celini gospodarsko vse bolj vplivna, pa je njen učinek na lokalne družbene odnose še vedno zelo omejen. Kot je razvidno iz angolskega primera, je interakcija domačinov s Kitajci skromna (zlasti zaradi jezikovnih ovir), saj prihajajo v stik večinoma le s trgovci na drobno in malimi podjetniki, ne pa tudi s kitajskimi delavci, ki sodelujejo pri velikih gradbenih ali drugih projektih kitajskih investitorjev in izvajalcev. Več kot tretjina v raziskavi sodelujočih Angolcev ima negativen odnos do kitajskih priseljencev, še bistveno večji delež pa je skeptičen do pretiranega navezovanja na Kitajsko ter jasno prepoznava tako pozitivne kot tudi negativne učinke obstoječega sodelovanja.

Posamezne afriške države so v pogajanjih z gospodarsko velesilo Kitajsko v močno podrejenem položaju, zato bi morale nastopati bolj povezano in okrepiti moč že obstoječih regionalnih gospodarskih povezav na celini. Z gospodarskim in političnim sodelovanjem 
bi lahko bolj odločno nastopile proti razprodaji svojih naravnih virov in se zavzemale za dolgoročno socialno-ekonomsko in okoljsko ugodne investicije.

\section{Viri in literatura}

African economic outlook 2013. 2013. African Development Bank, Organisation for Economic Co-operation and Development, United Nations Development Programme, Economic Commission for Africa, 357 str. URL: http://www.undp.org/content/dam/ rba/docs/Reports/African\%20Economic\%20Outlook\%202013\%20En.pdf (Citirano 20. 12. 2013).

Angola: Oil, broad-based growth, and equity. 2007. Washington, The World Bank, 214 str. URL: https://openknowledge.worldbank.org/handle/10986/6759 (Citirano 25. 9. 2013).

Atlas der Globalisierung. 2009. Paris, Le Monde diplomatique; Berlin, Taz Verlag, 213 str. Atlas der Globalisierung. 2012. Paris, Le Monde diplomatique; Berlin, Taz Verlag- und Vertriebs GmbH, 176 str.

Between extremes. China and Africa. 2012. Africa Research Institute. URL: http://www. africaresearchinstitute.org/files/briefing-notes/docs/Between-extremes-China-and-Africa-P2E56236DQ.pdf (Citirano 25. 9. 2013).

Bessa, C., 2011. China quer aumentar áreas de cooperação. Journal de Angola. URL: http://jornaldeangola.sapo.ao/27/0/china_quer_aumentar_areas_de_cooperacao (Citirano 10. 5. 2012).

BP Statistical review of world energy. June 2013. 2013. London, British Petroleum, 45 str. URL: http://www.bp.com/content/dam/bp/pdf/statistical-review/statistical_review_of_world_energy_2013.pdf (Citirano 8.10.2013).

Campos, I., Vines, A., 2008. Angola and China: a pragmatic partnership. London, Center for Strategic and International Studies, 26 str. URL: http://www.csis.org/media/csis/ pubs/080306_angolachina.pdf (Citirano 17. 8. 2012).

China-Africa economic and trade cooperation. 2013. Information Office of the State Council, The People's Republik of China. URL: http:/news.xinhuanet.com/english/ china/2013-08/29/c_132673093.htm (Citirano 25. 9. 2013).

Economic development in Africa report 2013. 2013. Geneva, United Nations Conference on Trade and Development, 146 str. URL: http://unctad.org/en/PublicationsLibrary/ aldcafrica2013_en.pdf (Citirano 1.8.2013).

Gorenc, T., 2011. Intervjuji avtorja v Bengueli, Huambu in Luandi.

Hobbs, J. J., Salter, C. L., 2006. Essentials of world regional geography. 5th ed. Avstralija itd., Thomson Brooks/Cole, 687 str.

Horta, L., 2011. Angola and paradox of China power. Diplomatic courier: a global affairs magazine (17. 8. 2011). URL: http://www.diplomaticourier.com/news/regions/africa/ 237-angola-and-the-paradox-of-chinese-power (Citirano 7. 8. 2012).

Human development report 2013. The rise of the South: human progress in a diverse World. 2013. New York, United Nations Development Programme, 202 str. URL: http://hdr. undp.org/sites/default/files/reports/14/hdr2013_en_complete.pdf (Citirano 19. 9. 2013). 
Ighobor, K., 2013. China in the heart of Africa. Africa renewal, 26, 3, str. 6-8. URL: http://www.un.org/africarenewal/magazine/january-2013/china-heart-africa (Citirano 1. 8. 2013).

Lirong, L., 2011. The EU and China's engagement in Africa: the dilemma of socialisation. Paris, European Union Institute for Security Studies, 41 str. URL: http://www.iss. europa.eu/uploads/media/The_EU_and_Chinas_engagement_in_Africa.pdf

(Citirano 1. 8. 2013).

News24. Angola gives Chinese 116 visas a day. 2013. URL: http://www.news24.com/Africa/News/Angola-gives-Chinese-116-visas-a-day-20130114 (Citirano 9. 10. 2013).

UNCTAD handbook of statistics 2012. 2012. Geneva, United Nations Conference on Trade and Development, 478 str.

Vintar Mally, K., 2012. Geografija Podsaharske Afrike. Ljubljana, Znanstvena založba Filozofske fakultete, 245 str.

World investment report 2013. 2013. Global value chains: investment and trade for development. New York, Geneva, United Nations, 236 str. URL: http:/unctad.org/en/ PublicationsLibrary/wir2013_en.pdf(Citirano 2. 8. 2013).

\section{ECONOMIC CO-OPERATION OF AFRICAN COUNTRIES AND CHINA:THE CASE OF ANGOLA}

\section{Summary}

In the first decade of the 21st century, Sino-African economic ties strengthened significantly. According to the Chinese white paper on China-Africa economic and trade cooperation (2013), China has become Africa's largest trade partner whereas Africa is China's major import source, second largest overseas market for construction projects, and fourth largest investment destination. There has been a huge increase in the volume of China-Africa trade as well as in the Chinese foreign direct investment. Main Africa's exports to China are fuels, ores, and precious stones, while imports consist mainly of Chinese manufactured goods. The latter is expected due to the low level of industrialization in the majority of African countries. However, there are many indications that cheap imported goods are destroying small and medium-sized local businesses. Almost one third of China's foreign direct investment in Africa is in mining, followed by investments in finance, building industry, and manufacturing. Most of China's development assistance is allocated to the construction and improvement of ports, roads, energy supply and telecommunications. In Africa, infrastructure investments and the exploitation of natural resources are by tradition closely linked.

Western countries are generally critical of the Chinese economic activities (i.e. competition) on the African continent, as they are believed to neglect social and environmental problems. Also, this economic co-operation has not been able to create new jobs for African workers, which would be one of the most desired goals for the future, together with investment in manufacturing and products with higher value added. 
Despite China's economic influence, its impact on local social relations is still very limited, as shown in the case of Angola.

The economy of Angola is nowadays based on oil exports and since the ceasefire agreement (2002), the economic growth has been very fast and other indicators favourable as well. Apart from the end of the war, China's financial aid was of key importance for economic development. China invested billions of USD in this politically unstable country and empowered its economy. At the same time, China gained access to Angolan natural resources and expanded its market.

Economic co-operation between Angola and China has brought about some impacts on Angolan society, too. According to certain estimates, there are up to 250,000 Chinese citizens living and working in Angola. Local inhabitants have little contact with immigrants. Mostly, they come into contact with Chinese retailers and small entrepreneurs. More than one third of the survey participants expressed negative attitude towards Chinese immigrants and even larger proportion of them is skeptical about economic overreliance on China. They clearly recognize positive and negative effects of existing cooperation. Their negative attitude towards Chinese immigrants is mainly accompanied by the fear of losing employment, land or other resources. This antipathy could be strengthened by further immigration and economic impacts.

(Translated by the authors) 